\title{
Nutrition Status of Under 5 Years Children Pre and Post Intervention Feeding Parenting In The Village Sangkima Kutai National Park East Kalimantan
}

\author{
${ }^{1}$ Bernatal Saragih, ${ }^{2}$ Bernaulus Saragih, ${ }^{3}$ Apul Sitohang, ${ }^{4}$ Netty Maria Naibaho \\ and ${ }^{1}$ Nova Solina Purba \\ ${ }^{1}$ Agriculture Product and Technology, Agriculture Faculty, University of Mulawarman Jl. Pasir Balengkong \\ Kampus Gunung Kelua Samarinda, East Kalimantan, Indonesia 75123 \\ ${ }^{2}$ Forestry Faculty University of Mulawarman Jl. Kihajar Dewantara Kampus Gunung Kelua Samarinda, East \\ Kalimantan, Indonesia 75123 \\ ${ }^{3}$ Agriculture Product and Technology, Agriculture Faculty, St. Thomas Catholic University, Jl. Setia Budi No. \\ 479 F Medan, North Sumatera, Indonesia 20132 \\ ${ }^{4}$ State of Agrucluture Polytechnic Samarinda, Jl. Samratulagi Kampus Sei Kledang, Samarinda, East
} Kalimantan, Indonesia 75131

\begin{abstract}
Improving the diet of children in the context of improving the nutritional status is a very important thing done by the parents (mothers). Methods of management and the provision of food at home by the mother is crucial to support health in infants. This study used a pre-experimental design (one pre and post test design). Intervention programs on parenting fed to mothers of children under five years in the village of South Sangata Sangkima District of East Kutai Regency. Data analysis used t-test and descriptive analysis method. Mother has a good knowledge of nutrition 45\%, being 50\% and less than 5\%. Understanding of the signs of child undernourishment were answered correctly by only $35 \%$. Mothers who give parenting practice good eating by $30 \%$, being $30 \%$ and less than 40\%. The food consumed by the child at each meal was answered by respondents spent as much as $27.5 \%$. Treatment gives food for children always given precedence over other family members carried by the mother as much as $30 \%$. Parenting children before intervention meal, have a good nutritional status $79.25 \%$, 16.98\% undernourishment and malnutrition 3.77\%. After three months of meal parenting intervention on maternal, child nutrition has a good percentage increased to $84.91 \%$ and undernourishment decreased to $11.32 \%$ before intervention was $16.98 \%$. Deviations nutritional status of children compared to the WHO 2005 reference data is widening with the increasing age of the child.
\end{abstract}

Keywords: intervention, parenting meal, nutritional status

\section{Introduction}

Decentralization policy promises hope for the creation of rural development based on local food, but if no caution decentralization will only pass on the way for the exploitation of capitalism in the rural sphere. Therefore, the commitment of all stakeholders at the national and local level should strive to achieve food security which leads to nutrition status. Food security and poverty are two serious problems in development. The number of poor people in East Kalimantan until the end of 2013 there are still tens of thousands of lives. The threat of poverty, food insecurity and malnutrition in infants and toddlers in need of serious attention by all elements of the nation. Poverty is a situation where there is a shortage of things common to such belongs food, clothing, housing and drinking water, these things are closely related to quality of life.

Family-style meals, which allow children to serve themselves from communal dishes, are widely endorsed. The rationale is that allowing children to serve themselves helps to promote autonomy and selfregulation in eating by allowing them to make food choices while providing opportunities for them to develop motor and social skills related to eating [1,2].

Family food insecurity will lead to starvation. Hunger is a condition in which the body is still in need of food, usually when the stomach was empty either intentionally or unintentionally for a long time. Hunger is not addressed and allowed to continue to occur then it can adversely impact the community: nutritional status, growth disorders, the intelligence of children, vulnerable to disease, high infant mortality rates, thus leading to high public spending on health. One interesting study that can be used as the basis for formulating a toddler nutrition improvement based on the resource potential of my family (society) is to learn from the positive deviation in the case of public nutrition improvement [3]. Improvements in household food security and diet diversity, whereas coverage with child care and disease-control interventions improved for most outcomes and provide encouraging evidence that a package of multi sector interventions has the potential to produce reductions in childhood stunting [4]. 
The choice of location studies were conducted in villages purposively Sengata Sangkima South East Kutai districts, because this village has malnutrition and undernourishment highest in the south region Sangata community health centers. The village is located Sangkima forest region (Kutai National Park). This area originally existed as forest inventory with broad 2,000,000 ha. During Kutai existence has never been free from conflict of interest. Based on existing data, within a period of 63 years starting from 1934 to 1997, the region continues to experience a drastic reduction in the area of 198,629 ha whereas the administration of government, with an area of 198,629 ha area is located in the East Kutai Regency $( \pm 80 \%)$, Kutai regency $( \pm 17.48 \%)$ and Bontang $( \pm 2.52 \%)$. Kutai National Park has a flat topography that is spread almost the entire area of the region $(92 \%)$ and undulating to hilly scattered in the central part of the area that stretches north-south direction $(8 \%)$. Most of the region has a height class between 0-100 m altitude (61\%) were spread on the eastern and western regions. The level of the height of the center of the area between 100-250 m altitude (39\%).

Nutritional status of children is strongly associated with the ability of mothers in parenting. Current methods of persuasion to persuade children less likely to eat and methods of processing, the provision of food at home by the mother is crucial to support health in infants, so the impact of the intervention study conducted parenting meal the nutritional status of under 5 years children.

\subsection{Design Research and places the research}

\section{Methods}

The design used in this study was pre experimental design (one pre and post test design). The experiment was conducted in the Kutai National Park villages Sangkima Sengata District of South, East Kutai Regency, East Kalimantan, Indonesia.

\subsection{Sampling Techniques and Data Collection Method}

The population is all housewives who have children (6-59 months) in the area of health centers and integrated health Sangkima, East Kutai district. Samples was mothers of infants under five years were involved as respondents $(n=40)$. The primary data obtained through interviews based on the questionnaire that the respondent characteristics of data, knowledge of nutrition, parenting meal and weighing. Secondary data includes data obtained from various sources such as employee community health centers, and rural areas Sangkima. Primary data were collected through interviews using a questionnaire covering family characteristic data; child's age and weighing of the children. After weighing under five be giving a questionnaire about knowledge of nutrition and parenting a child to meal at answered by respondents. Then do the parenting intervention on meal by researchers who performed for 2.5 hours and then after 3 months post-intervention measurements performed again nutritional status of children, to determine of children's nutritional status. Data obtained with the nutritional status of children weighing and age (Z-score of weigh/age) with the 2005 WHO reference standard. The WHO Global Database on Child Growth and Malnutrition uses a Z-score cut-off point of <-2 SD to classify low weight-for-age, and <-3 SD to define severe undernutrition. The formula for calculating the Z-score is:Z-score (or SD-score) = (observed value - median value of the reference population) / standard deviation value of reference population [8].

\subsection{Data analysis}

The data collected were processed and analyzed using computer software. Compares the means between two related groups on nutrition status pre and post intervention used by T-test with software.

\subsection{Characteristics of Mother}

\section{Results and Discussion}

Most of the mothers had a job as a housewife that is $87.5 \%$, and $7.5 \%$ private and work as farmers by $5 \%$. The number of mothers aged 25-35 years of 57.5\%, less than 25 years was $27.5 \%$ and over 35 years by $15 \%$. Mothers who have a junior high school education was $32.5 \%, 22.5 \%$ had elementary education and high school education by $20 \%$.

\subsection{Nutrition Knowledge of Mother}

Mother with a good knowledge of the category by $40 \%, 45 \%$ adequate, and less than $5 \%$, categorized mothers have less nutritional knowledge, if answered questions correctly is less than (60\%), moderate (> 60$76 \%$ ) and good (> $76 \%)$ ]. An average of 10 nutrition knowledge questionnaire that could be answered by the mother properly was $5.05+3.64$ with a minimum of 3 and a maximum of 10 to a mother who can answer ten nutritional knowledge questionnaire for 3 people. Based on respondents' answers ten questions, respondents who answered the question of how often you should weigh babies and infants ?, correctly answering 1-2 months a total of 35 respondents $(87.50 \%)$. What is the purpose of weighing on a regular basis? Knowing correctly answering nutritional status by 22 respondents (55\%). How to assess your baby and infants nutrition enough? 
Correctly answering weight infants / infants is above the red line on the Health Card (KMS) number 24 (60\%). The best food for babies was breast milk that answer by 32 (80\%). What's that exclusive breastfeeding? Who answered correctly by giving only breast milk for babies aged 0-6 months without other complementary food number 20 (50\%). Did advantage breastfeeding mothers? Correctly answering the baby's immune Build, cheap, close relationship between mother and child as much as 37 (92.5\%). The choice of the most nutritious diet was white rice, chicken, vegetables, bananas, milk of $34(85 \%$.

Salt was good for consumption of iodized salt correctly answering as many as 34 respondents $(85 \%)$. Signs of malnourished children was dull hair, less weight, correctly answering as many as 14 (35\%). Vitamins are usually given in a health center was vitamin A in infants who answered correctly were 36 respondents $(90 \%)$. Of the ten questions about correct nutrition knowledge is less than $60 \%$, was the question of the purpose of weighing, exclusive breastfeeding and understanding the signs of malnutrition in children. Understanding of the signs of child malnutrition is very low even correctly answer only $35 \%$.

\subsection{Food Habits Pattern}

Parenting children meal poorly in the study sample was $40 \%$, moderate $30 \%$ and good by $30 \%$, good parenting categorized with scores $(>80 \%)$, moderate $(60-80 \%)$ and poor $(<60 \%)$. An average of 13 questionnaires parenting meal that can be answered by the mother was $7.13 \pm 2.89$ with a minimum value of 2 and a maximum of 11. Based on the respondents' answers to thirteen questions, the mother feeding a child in a day 3 times was 33 respondents $(82.5 \%)$. Feeding time is given regularly by 27 respondents $(67.5 \%)$. Type of food given to the child every child eat in a day, with a different type of mom every meal as much as 12 respondents $(30 \%)$. Variety of food provided to children, mothers always so diverse done by a total of 18 respondents (45\%). The food is always given qualified four of five perfectly healthy (staple food, some side dishes, vegetables, fruits and milk) done by the mother as much as 17 respondents $(42.5 \%)$. Reaction child each meal, Glad (shows interest in food) on the child's mother were 21 respondents $(52.5 \%)$. Mother did the situation created at mealtime fun for children (while playing) done by the mother as much as 27 respondents $(67.5 \%)$, in others with sometimes fun for kids, sometimes boring, and there is also boring in children (over the kitchen table / the same place every day).

The food consumed by the child at each meal as much as 11 respondents $(27.5 \%)$. If the child does not want meal, what mothers do mothers do by persuading as many as 37 respondents $(92.5 \%)$, in others by forcing or letting. Mothers who make assistance is always done by the mother while eating a total of 29 respondents (72.5\%). Mother who always give street food in children done by the mother as much as 8 respondents $(20 \%)$. Treatment of food for children always given precedence over other family members done by the mother as much as 12 respondents $(30 \%)$, others occasionally or never. Mothers are always preparing food for children meals as much as 33 respondents $(82.5 \%)$.

Children's energy intake of the entrée or meal, on average, was not influenced by self-serving, but results provide evidence of individual differences in children's serving behaviors and intake. Self-selected portion sizes were not associated with weight status. However, children who were more responsive to increasing portion sizes, defined by individual slope estimates relating ad libitum intake of the entrée across a range of entrée portions, selected larger entrée portions and consumed more energy when given the opportunity to selfserve the entree [5]. Adult support, important for self development and help children's behavior. Allowing children to serve themselves as part of the family diet, to include a variety of social and motor skills are relatively advanced $[6,7]$.

\subsection{Nutritional Status of Under 5 Years Children Before and After Meals Parenting Intervention}

Nutritional status of children under five in this study assessed based on anthropometric index weight for age (W/A), based on an index that has been recommended by WHO 2006 [8]. Average z-score of nutritional status of infants is $-1.24+1.11$ with a $\mathrm{z}$-score is -4.82 and the minimum value of the maximum $\mathrm{z}$-score was 1.78 . Nutritional status based on z-score of weight / age showed the same thing the increasing age showed a trend of nutritional status of children under five has increasingly deviated from the standard of reference (Fig.1 and 2)

Results of a study conducted by Saragih et al. (2007) showed a baby boy on the fortification group (mothers during pregnancy were receiving food multi-micronutrient fortified substances) are generally not far from the zero point (reference) even at 6 months of age z-score of a baby boy on the value of the zero point. In general, this study found deviation in the growth occurs in infants aged 2 months ie in the control group. While the group without fortification which tends to be slower at 4 months of age infants. Such deviations more pronounced in female infants than male infants [9]. Deviation of growth in male babies far from the control group zero point occurs in the first month by reference to the WHO 2006 [8]. 


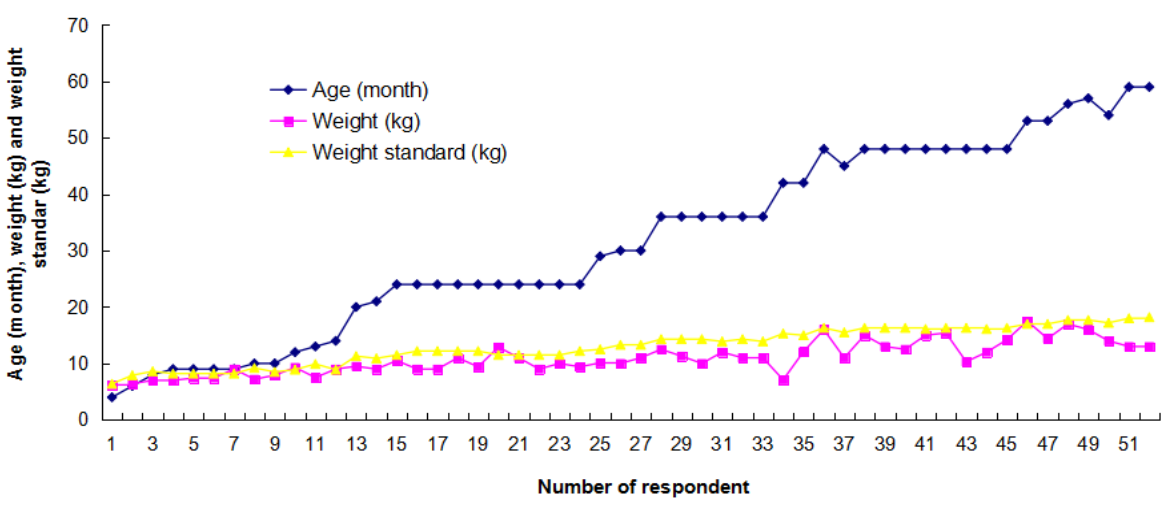

Fig.1: Weigh, age and weight standard (WHO, 2005) under 5 years children pre meals parenting intervention

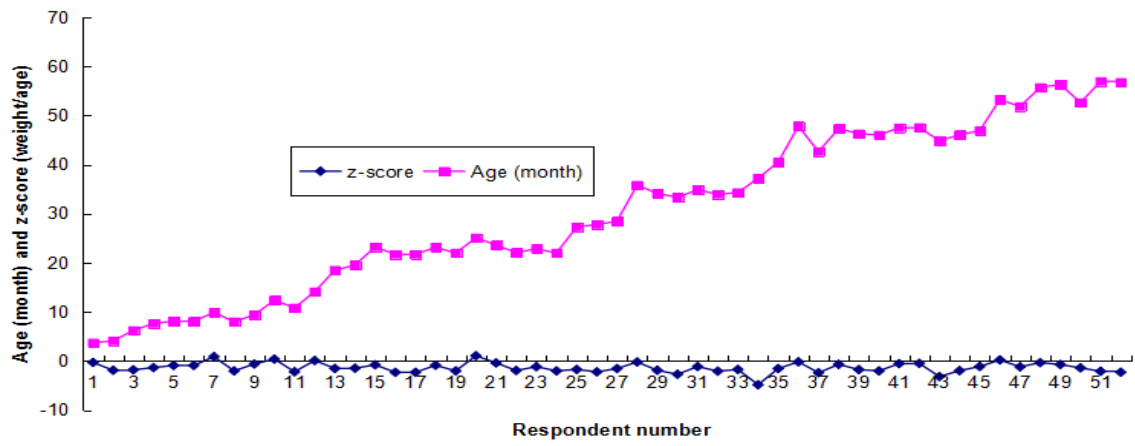

Fig.2: Nutrition status (z-score weight/age) under 5 years children pre meals parenting intervention

Parenting eat better course would provide the growth and development of children better in this study, indicating the parenting intervention on maternal eating does not give a response in child nutrition pre (before eating parenting intervention) compared with the post (after the intervention pattern parenting children eat 3 months). Children's nutritional status before intervention eat parenting children with good nutrition by 79.25 percent, 16.98 percent undernourishment and malnutrition 3.77 percent, while after 3 months post intervention parenting a child eating with good nutritional status at 84.91 percent, 11.32 percent undernourishment and malnutrition 3.77 percent (Fig.3). Paired T test results with test showed no significant correlation of nutritional status before and after intervention $(\mathrm{p}=0.113 ;>0.05)$

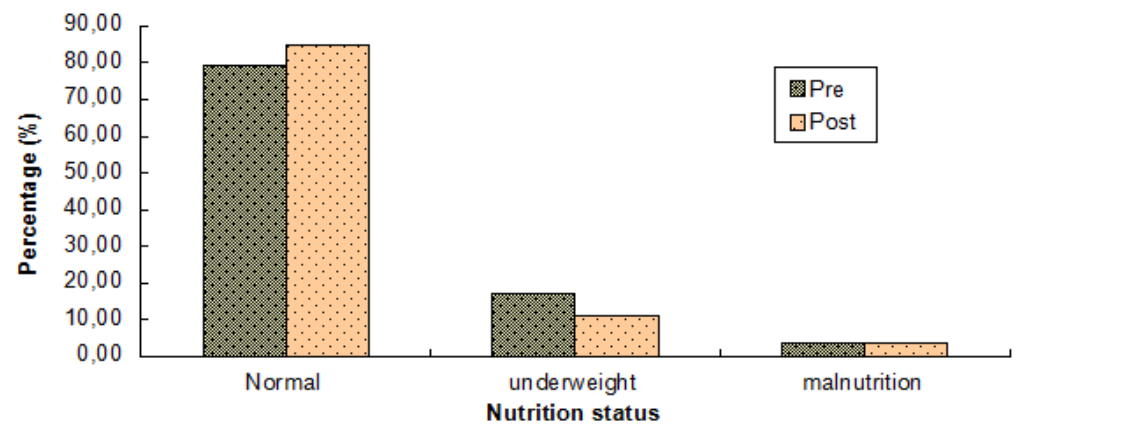

Fig.3: Nutrition status under 5 years children pre and post meal parenting intervention

Parenting significantly affect infant weight gain, the better parenting (parenting eating, health and play) then the better growth [9]. Several studies have shown that feeding practices and poor processing hygiene so as to increase the risk of disease, especially infection. The results showed that early supplementary feeding was associated with lower nutritional status of infants. This is attributed to the low quality of the food given breast milk intake is also reduced. Besides the negative impact of feeding such as high levels of morbidity, especially diarrhea, in addition to the poor quality of food and breast milk intake decreases. Infection, poor nutritional status and reduced breast milk intake that will have an impact on the growth and development of infants. 


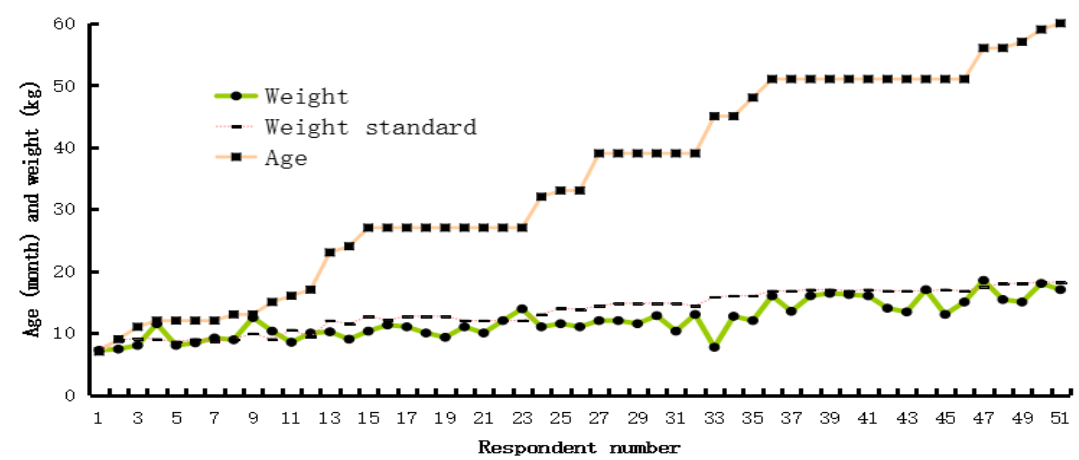

Fig. 4: Weight, age and weight (standar WHO) under 5 years children post mother eating parenting intervention

As part of the family, the baby food consumption is highly dependent on family food consumption. Food insecurity family will cause a lack of nutrient intake in infants. It is characterized by decreasing physical abilities, impaired growth and development as well as the morbidity and high infant mortality. That situation can occur due to a direct effect between food consumption and nutritional status of infants. Mothers who have a good knowledge of baby food and know how to provides food and arranged for the food available to eat her son will make good nutritious baby.

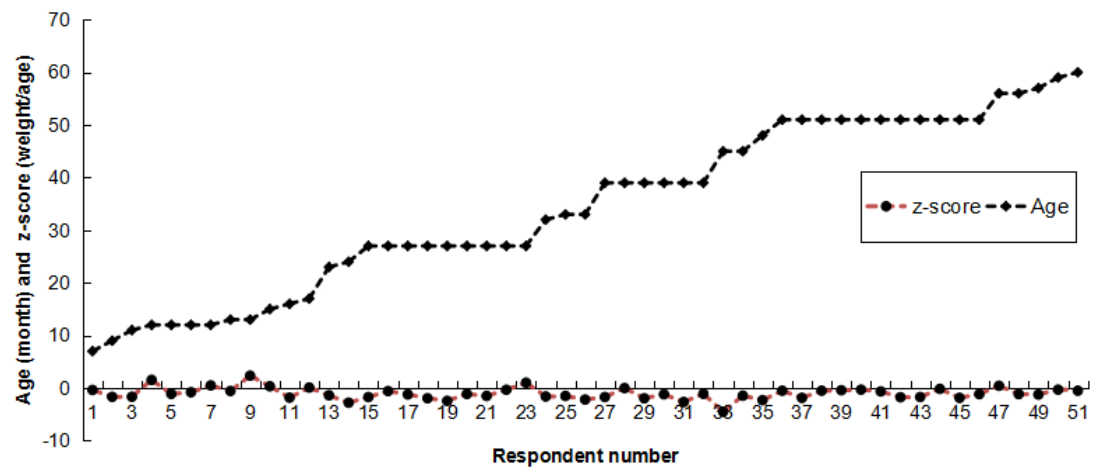

Fig.5: Age and nutrition status (z-score weight/age) under 5 years children post meal parenting intervention

Based on the growth response in Fig. 4 and 5 provides evidence that the growth, development and nutritional problems are multi-dimensional problem, affected by various factors. The immediate cause undernourishment is not eating a balanced, both the number and quality of nutritional intake, in addition to the intake of nutrients can not be optimally utilized by the body due to impaired absorption due to infectious disease. The cause is not immediately available is not enough food in the household, lack of good parenting, especially in feeding patterns in infants, inadequate sanitation and environmental health and the poor health services. All of these conditions is closely related to low levels of education, income and poverty levels. The root of the problem of nutrition is the economic crisis, political and social events, including natural disasters, which affect the imbalance between food intake and the presence of infectious diseases, which in turn affects the nutritional status of children

The practice of eating good parenting is done by the mother will certainly help in improving child nutrition, although in this study showed differences in nutritional status (z-scores) have not demonstrated change after 3 months (Fig. 6) meal parenting intervention.

Child care is manifested as feeding, caring for and guiding (push and cognitive stimulation of the child). In addition to parenting meal, various studies have shown that the scarcity of resources associated with low incomes lead to food insecurity. Interaction financial planning and revenue associated with food insecurity $(\mathrm{P}=0.003)$. Have good financial skills in the future have a minimal effect on food insecurity [10].

Family diet, provide support to the children from the beginning to serve themselves from the plate itself is also a good pattern in the care of children in accordance with its development stage. By allowing children to serve themselves help to promote self-reliance and self-regulation of meal by allowing them to make food choices while providing an opportunity for them to develop motor and social skills related to meal [1,2]. 


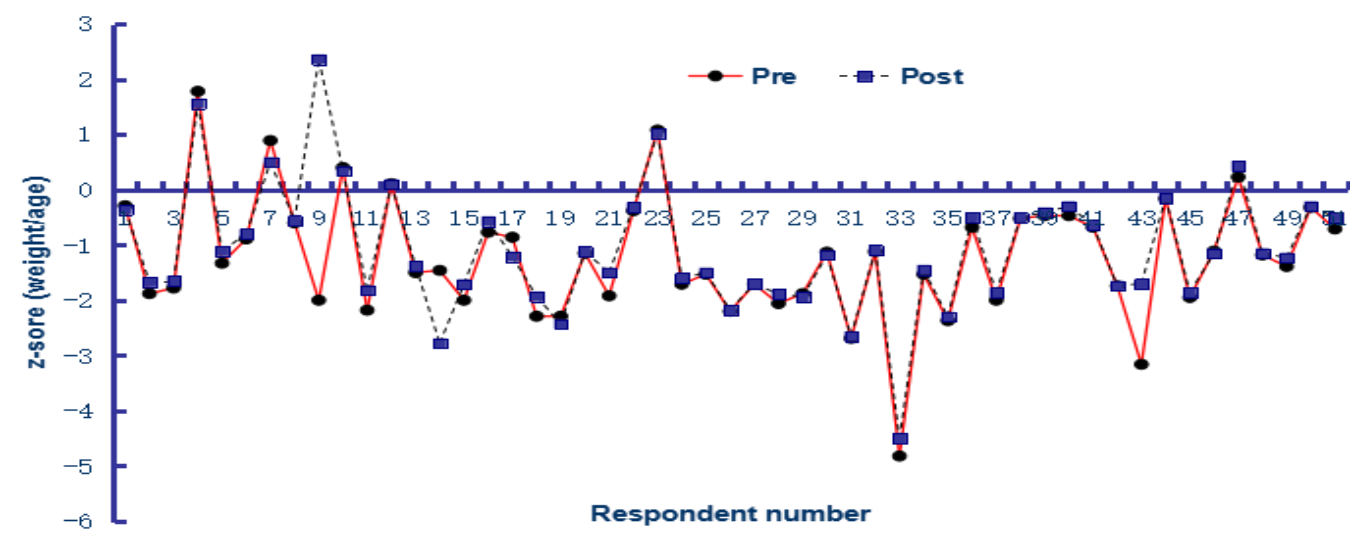

Fig. 6: Nutrition status (z-score;weight/age ) under 5 years children pre and post meal parenting intervention

One study in 44 preschool children found that the average mid-morning and afternoon food intake was significantly greater when the children were allowed to serve themselves than when presented fixed amount proportional [11]. Another study found that children aged 3-6 years consume less than 25\% when most of the dishes they served food dishes than self-serving. These findings suggest that allowing children to serve themselves can help prevent excessive energy intake at meals [12].

\section{Conclusion}

Mother has a good knowledge of nutrition $45 \%$, being $50 \%$ and less than $5 \%$. Understanding of the signs of child undernourishment is low, who answered correctly only $35 \%$. Mothers who provides parenting practice good eating by $30 \%$, being $30 \%$ and less than $40 \%$. The food consumed by the child at each meal was answered by respondents spent as much as $27.5 \%$. Feeding with always put children than other family members done by the mother as much as $30 \%$. Under five baby before meal parenting counseling interventions have a good nutritional status by $79.25 \%$, amounting to $16.98 \%$ undernourishment and malnutrition of $3.77 \%$. three months post-intervention parenting toddlers meal good nutrition percentage of $84.91 \%$ and $11.32 \%$ for undernourishment. Paired T test results with test showed no significant correlation of nutritional status before and after meal parenting intervention ( $p=0.113 ;>0.05)$. Parents need to improve the quality of care in the practice of feeding including breast feeding, supplementary feeding quality, preparation and storage of food hygiene.

\section{Acknowledgements}

Thank submitted to the Directorate General of Higher Education of the Republic of Indonesia on Aid Scheme Competitive Research Fund by 2013-2014

\section{References}

[1]. J.O. Fisher, Effects of age on children's intake of large and self-selected food portions. Obesity (Silver Spring) 15, 2007, 403-12

[2]. M Sigman-Grant, E. Christiansen, L.Branen, J. Fletcher, S.L.Johnson, About feeding children: mealtimes in child-care centers in four Western states. J Am Diet Assoc 108, 2008:340-346.

[3]. M. Ahrari, R.F.Houser, S.Yassin, M.Mogheez, Y. Hussaini, P.Crump, A Positive Deviance-Based Antenatal Nutrition Project Improves Birth-Weight In Upper. Egypt J Health Popul Nutr 24(4), 2006, :498-507

[4]. R. Remans, P.M.Pronyk, J.C.Fanzo, J.Chen, C.A.Palm, Multisector intervention to accelerate reductions in child stunting: an observational study from 9 sub- Saharan African countries, Am J Clin Nutr 94, 2011, 1632-1642 doi:10.3945/ajen.111.020099

[5]. J.S.Savage, L.Haisfield, J.O.Fisher, M.Marini, and L.L.Birch, Do children eat less at meals when allowed to serve themselves? Am J Clin Nutr July 96, 2012, 36-43; doi:10.3945/ajcn.112.035261

[6]. E. Addessi, A.T.Galloway, E.Visalberghi,L.L. Birch, Specific social influences on the acceptance of novel foods in 2-5-yearold children. Appetite 45, 2005, 264-271.

[7]. J.B. Robinson, B.M. Burns, D.W. Davis, Maternal scaffolding and attention regulation in children living in poverty. $J$ Appl Dev Psychol. 30, 2009, 82-91.

[8]. [WHO] Word Health Organization. 2006. WHO child growth standards. WHO, Geneva

[9]. B. Saragih, H. Syarif, A. Nasoetion, H.Riyadi, The effect of food fortification multi micronutrients in pregnant women on the growth of linear, high knees and anemia status of infants, Indonesian Journal of Nutrition 30 (1) 2007,12-24

[10]. L.H.Epstein, N. Jankowiak, H.Lin, R.Paluch, M.N.Koffarnus and W.K.Bickel, No food for thought: moderating effects of delay discounting and future time perspective on the relation between income and food insecurity. Am J Clin Nutr 100, 2014, 884-890; doi:10.3945/ajcn.113.079772

[11]. D.L.Jahnke and P.A.Warschburger, Familial transmission of eating behaviors in preschool-aged children. Obesity (Silver Spring) 16, 2008, 1821-5.

[12]. G. Mrdjenovic and D.A.Levitsky, Children eat what they are served:imprecise regulation of energy intake. Appetite 4, 2005, 273-282. 